\title{
Dielectric Studies of Double Sintered Lithium Zinc Nickel Ferrite Prepared by Citrate Precursor Method
}

\author{
Ibetombi Soibam $^{1, *}$, N Nilima ${ }^{2}$, S Phanjoubam ${ }^{2}$ \\ ${ }^{1}$ Department of BS\&H (Physics), NIT Manipur, Takyel, Imphal, India \\ ${ }^{2}$ Department of Physics, Manipur University, Canchipur, Imphal, India \\ *Corresponding author: ibetombi96@gmail.com
}

Received July 14, 2014; Revised July 21, 2014; Accepted July 27, 2014

\begin{abstract}
Ni substituted $\mathrm{Li}-\mathrm{Zn}$ ferrites with compositional formula $\mathrm{Li}_{0.4-0.5 \mathrm{x}} \mathrm{Zn}_{0.2} \mathrm{Ni}_{\mathrm{x}} \mathrm{Fe}_{2.4-0.5 \mathrm{x}} \mathrm{O}_{4}$ where $0.02 \leq \mathrm{x} \leq 0.1$ in steps of 0.02 was fabricated by using citrate precursor method. X-ray diffraction was used to confirm the spinel phase. The dielectric constant was investigated as a function of composition, frequency and temperature. Room temperature dielectric constant showed a decrease with addition of $\mathrm{Ni}^{2+}$ ions. It was explained in terms of space charge polarization and koops two layer model. The variation in dielectric constant with frequency showed dispersion. Variation of dielectric constant with temperature was studied at different frequencies and an increase was observed as temperature rises. The possible mechanisms responsible for the above behavior are explained.
\end{abstract}

Keywords: lithium ferrites, citrate precursor, XRD, lattice parameter, dielectric constant, SEM

Cite This Article: Ibetombi Soibam, N Nilima, and S Phanjoubam, "Dielectric Studies of Double Sintered Lithium Zinc Nickel Ferrite Prepared by Citrate Precursor Method.” American Journal of Materials Science and Engineering, vol. 2, no. 2 (2014): 24-27. doi: 10.12691/ajmse-2-2-3.

\section{Introduction}

Lithium ferrites form an interesting material in the field of research. They have been found to be used in certain applications like biomedical drug delivery, magnetic resonance imaging (MRI), military devices, power transformers in electronics, read/write heads for high speed digital tape etc $[1,2,3]$. This is because of their properties like high resistivity, low loss, high Curie temperature, better temperature stability of saturation magnetization, square hysteresis loop etc. The properties of ferrites are tailored by changing the synthesis method, type of substitution, sintering conditions etc $[4,5]$. Among the synthesis method citrate precursor method is preferred as it is economic and convenient $[7,8,9]$. The role of substituent in modifying the properties of ferrites has been widely studied and $\mathrm{Ni}$ substitution has been found to decrease the conductivity and not much work reported. Moreover the study of effects of frequency and temperature on dielectric constant gives a greater understanding of dielectric behaviour of ferrites.

Thus, in the present work an investigation on the dielectric constant as a function of composition, frequency and temperature on Ni substituted Li-Zn ferrite is carried out.

\section{Experimental Details}

Nickel substituted lithium zinc ferrites with compositional formula $\mathrm{Li}_{0.4-0.5 \mathrm{x}} \mathrm{Zn}_{0.2} \mathrm{Ni}_{\mathrm{x}} \mathrm{Fe}_{2.4-0.5 \mathrm{x}} \mathrm{O}_{4}$ where $\mathrm{x}=0.02 \leq \mathrm{x} \leq 0.1$ in steps of 0.02 were prepared by the citrate precursor method. The precursor used was AR grade lithium nitrate, zinc nitrate, iron nitrate, nickel nitrate and citric acid. The preparation method have been reported elsewhere $[10,11]$. The sample was given presintering at $600^{\circ} \mathrm{C}$ followed by final sintering at $900^{\circ} \mathrm{C}$ for 8 hours in air at a slow heating rate of $5^{\circ} \mathrm{C} / \mathrm{min}$. and then furnace cooled. X-ray diffractometer (Phillips) with $\mathrm{CuK}_{\alpha}$ $\left(\lambda=1.5405 \mathrm{~A}^{\circ}\right)$ radiation was used to identify the spinel phase. The lattice constant and theoretical density was calculated from XRD data and their variation with composition studied. Agilent HP 4284A LCR meter was used for measuring capacitance and the value of dielectric constant was calculated using the formula $\varepsilon^{\prime}=\mathrm{Cd} / \varepsilon_{0} \mathrm{~A}$ where $C$ is the measured capacitance, $d$ the thickness, $A$ the cross sectional area of the sample and $\varepsilon_{0}$ the permittivity of free space. Dielectric behaviour of the synthesized samples was studied as a function of $\mathrm{Ni}^{2+}$ concentration and also the investigation of the dependence of dielectric constant with frequency $(100 \mathrm{~Hz}-1 \mathrm{MHz})$ and temperature $\left(20^{\circ} \mathrm{C}-150^{\circ} \mathrm{C}\right)$ was carried out.

\section{Results and Discussion}

\subsection{X-ray Diffraction Patterns}

Spinel phase structure of the prepared ferrite samples was confirmed using XRD pattern. Figure 1 shows the XRD pattern for all the samples. All peaks could be indexed to the standard pattern reported by the Joint Committee on Powder Diffraction Standards (JCPDS) for single phase spinel LiZnNi ferrite. No characteristic peak due to impurities is detected in the XRD pattern of all the samples. 


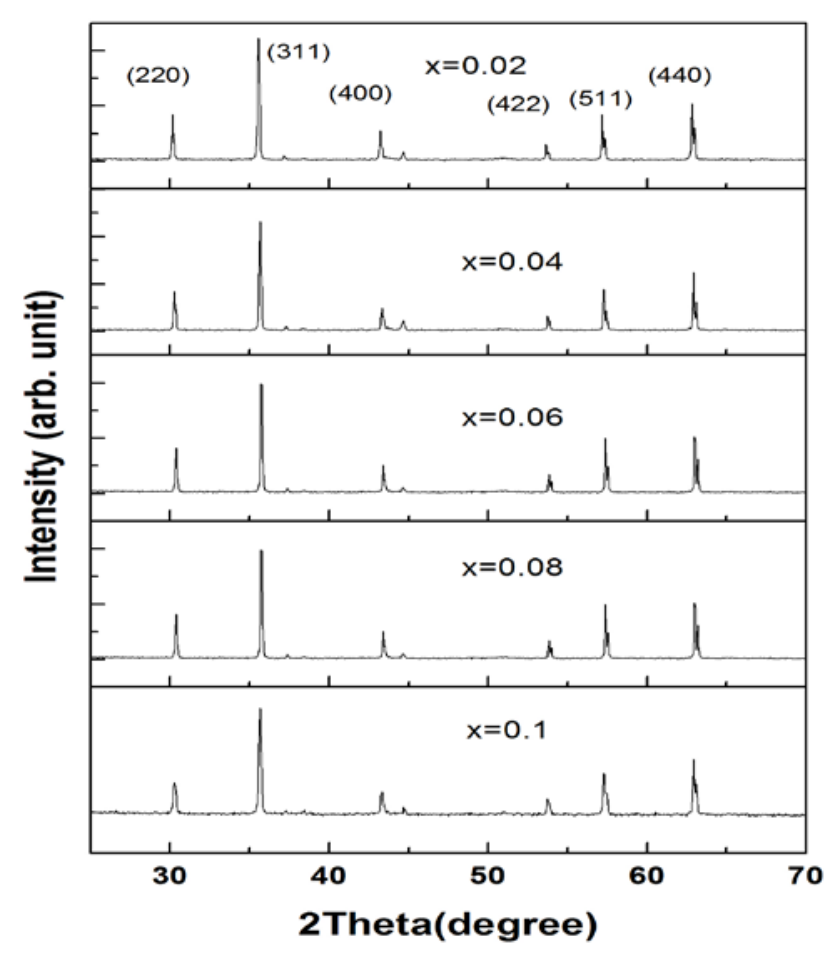

Figure 1. XRD pattern for $\mathrm{Li}_{0.4-0.5 \mathrm{x}} \mathrm{Zn}_{0.2} \mathrm{Ni}_{\mathrm{x}} \mathrm{Fe}_{2.4-0.5 \mathrm{x}} \mathrm{O}_{4}$

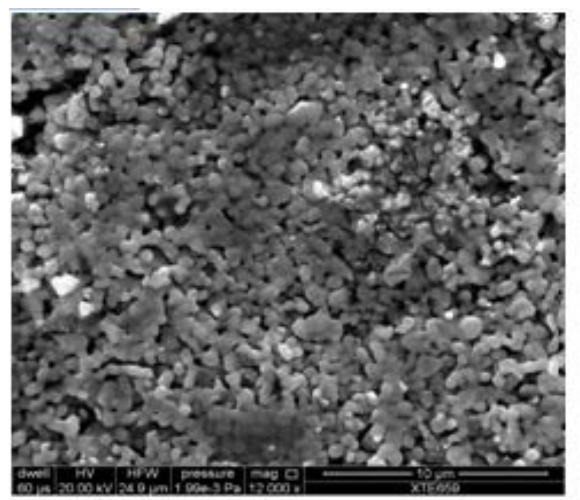

The lattice parameter calculated from the X-ray data showed a decrease with increase in $\mathrm{Ni}^{2+}$ concentration [Table 1]. In the formula $\mathrm{Li}_{0.4-0.5 \mathrm{x}} \mathrm{Zn}_{0.2} \mathrm{Ni}_{\mathrm{x}} \mathrm{Fe}_{2.4-0.5 \mathrm{x}} \mathrm{O}_{4}, \mathrm{Ni}^{2+}$ ions with radius $0.078 \mathrm{~nm}$ substitute $\mathrm{Fe}^{3+}$ ions and $\mathrm{Li}^{1+}$ ions with radius $0.067 \mathrm{~nm}$ and $0.078 \mathrm{~nm}$ respectively [12]. A linear increase in lattice parameter is therefore expected, but it was not observed. This may be due to dependence on factors like long range attractive coulomb forces, bond length etc. in spite of the dependence on ionic radius $[12,13,14]$. The theoretical density is calculated from the XRD data and is shown in Table 1 . The results are in agreement with observations by previous workers.

Table 1. Lattice parameter, density (theoretical and experimental) for $\mathrm{Li}_{0.4-0.5 \mathrm{x}} \mathrm{Zn}_{0.2} \mathrm{Ni}_{\mathrm{x}} \mathrm{Fe}_{2.4-0.5 \mathrm{x}} \mathrm{O}_{4}$ where $\mathrm{x}=0.02 \leq \mathrm{x} \leq 0.1$ in steps of 0.02

\begin{tabular}{|l|l|l|l|l|l|}
\hline Concentration. & $\mathbf{0 . 0 2}$ & $\mathbf{0 . 0 4}$ & $\mathbf{0 . 0 6}$ & $\mathbf{0 . 0 8}$ & $\mathbf{0 . 1}$ \\
\hline Lattice constant $\left({ }^{\circ} \mathrm{A}\right)$ & 8.3635 & 8.3485 & 8.3483 & 8.3389 & 8.3339 \\
\hline Theoretical density (gm/cc) & 4.904 & 4.919 & 4.920 & 4.923 & 4.944 \\
\hline
\end{tabular}

\subsection{SEM Analysis}

Typical SEM micrograph for concentration of $\mathrm{Ni}=0.02$ and 0.08 is shown in Figure 2. The particle sizes measured from SEM analysis was found to be in the nanometer range varying between $630 \mathrm{~nm}$ and $950 \mathrm{~nm}$.

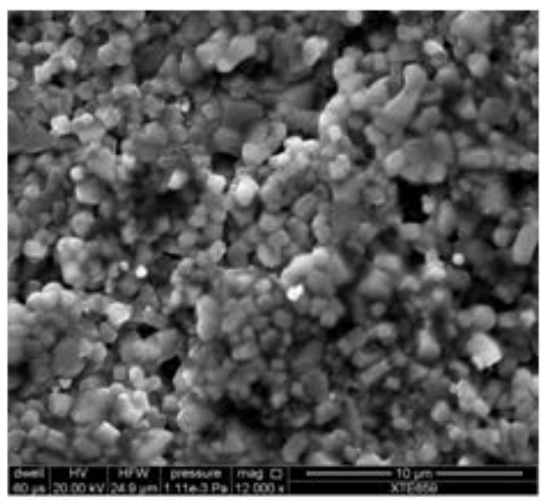

Figure 2. SEM micrograph for (a) $\mathrm{Ni}=0.02$, (b) $\mathrm{Ni}=0.08$

\subsection{Dielectric Properties}

The dielectric properties of the samples have been studied as a function of concentration, frequencies and temperature. The room temperature dielectric constant measured at $10 \mathrm{KHz}$ is found to decrease with $\mathrm{Ni}$ ion concentration and is shown in Figure 3.

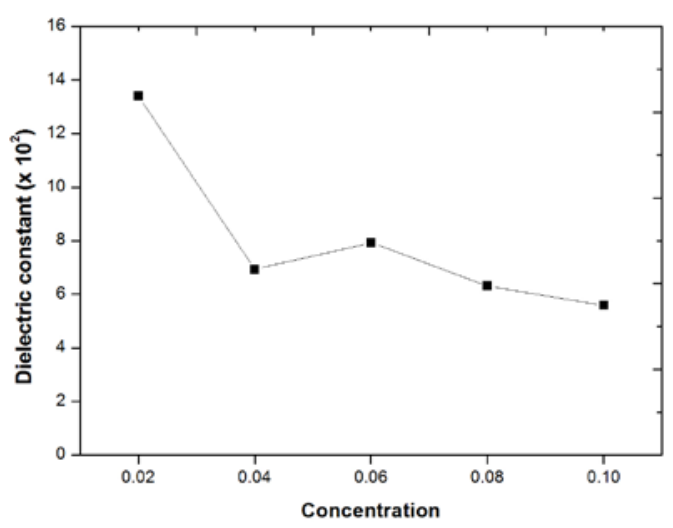

Figure 3. Variation of rt dielectric constant with concentration for $\mathrm{Li}_{0.4}$ ${ }_{0.5 x} \mathrm{Zn}_{0.2} \mathrm{Ni}_{\mathrm{x}} \mathrm{Fe}_{2.4-0.5 \mathrm{x}} \mathrm{O}_{4}$
The variation in the dielectric constant can be explained on the basis of space charge polarization and the Koop's two layer model where the ferrite is assumed to be made up of well- conducting grains separated by poor conducting layers or grain boundaries. The transport of charge carrier creates the space charge polarizations which are stopped at the grain boundary. This can also be understood by a mechanism similar to conduction mechanism. The electrical conduction in ferrite is explained by the Verwey mechanism of electron hopping $[15,16]$, where conduction takes place by hopping of electrons between $\mathrm{Fe}^{2+}$ and $\mathrm{Fe}^{3+}$ ions at $\mathrm{B}$ sites. The electrons, by hopping, reach the grain boundary and due to its higher resistivity, the electrons get piled up, thereby producing space charge polarization. In the present study, there is a change in the polarization with the substitution of $\mathrm{Ni}^{2+}$ ions. This can be understood by considering the cationic formula,

$\left(\mathrm{Zn}_{0.2} \mathrm{Fe}_{0.8}\right)\left[\mathrm{Li}_{0.4-0.5 x} \mathrm{Ni}_{\mathrm{x}} \mathrm{Fe}_{1.6-0.5 \mathrm{x}}\right] \mathrm{O}_{4}$. As $\mathrm{Ni}$ concentration is increased there is a decrease in $\mathrm{Fe}^{3+}$ ions at $\mathrm{B}$ sites and increase in $\mathrm{Ni}^{2+}$ ions at the $\mathrm{B}$ site. However, the exchange process of $\mathrm{Ni}^{2+} \leftrightarrow \mathrm{Ni}^{3+}$ is weak compared to $\mathrm{Fe}^{3+} \leftrightarrow \mathrm{Fe}^{2+}$, hence $\mathrm{Fe}^{3+} \leftrightarrow \mathrm{Fe}^{2+}$ is assumed to be the 
dominant mechanism [12]. This in turn decreases the piling up of electrons at the grain boundary, hence impeding the build up of space charge polarization. The value of dielectric constant therefore decreases. The sample with composition $\mathrm{x}=0.06$ behave anomalously showing a slight increase in dielectric constant. The $\mathrm{x}=$ 0.06 sample needs to be further investigated. Moreover the value of dielectric constant decreases with double sintering as compared to single sintering and the sintering effect needs to be studied.

Figure 4 shows the dependence of dielectric constant with frequency for all the samples. The dielectric constant shows dispersion in the frequency range under investigation. The value of dielectric constant is high at low frequencies, and decreases rapidly with increase in frequency and at a much higher frequency the dielectric constant is low and remains almost constant.

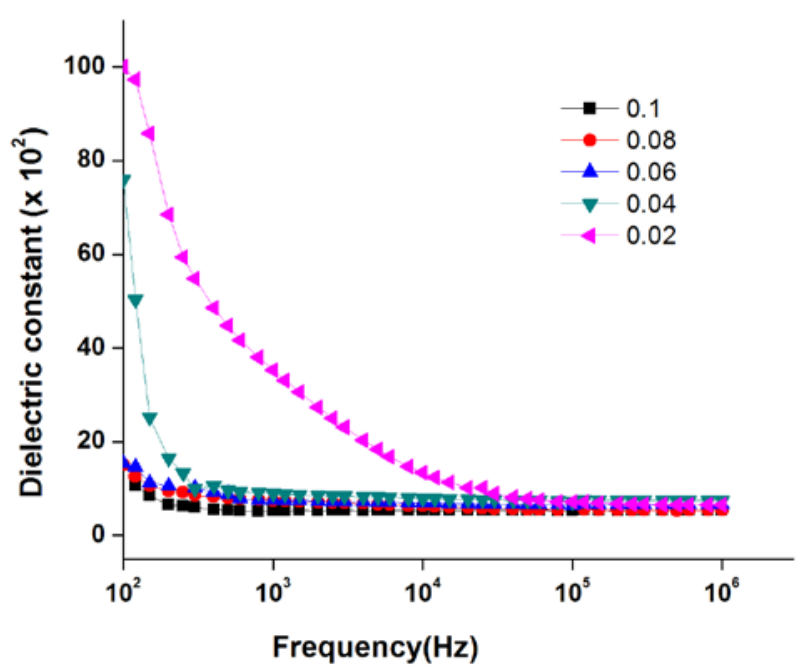

Figure 4. Variation of dielectric constant with frequency for $\mathrm{Li}_{0.4}$ ${ }_{0.5 x} \mathrm{Zn}_{0.2} \mathrm{Ni}_{\mathrm{x}} \mathrm{Fe}_{2.4-0.5 \mathrm{x}} \mathrm{O}_{4}$

The observed dispersion can be explained in terms of the space charge polarization and Koop's two layer model as has been mentioned before. Accordingly the number of available ferrous ions decreases with the increases in Ni concentration and thereby decreases the polarization of the ion. The dielectric constant is observed to reduce as the frequency of the externally applied field increases gradually,. This reduction occurs, because, beyond a certain frequency of the externally applied field the electronic exchange between $\mathrm{Fe}^{3+} \leftrightarrow \mathrm{Fe}^{2+}$ cannot follow the frequency of the alternating field. Hence a decrease in dielectric constant is observed. The variation in dielectric constant with frequency is different for different compositions which may be due to the fact that there are contributions arising from $\mathrm{Fe}^{2+}$ ions, $\mathrm{Ni}^{2+}$ ions, interfacial dislocation pile ups, oxygen vacancies, grain boundary defects, etc. But it is impossible to predict how each factor contributes. Similar observation has been reported by several workers [17,18,19,20].

The temperature dependence of dielectric constant for all samples at different frequency was investigated. Typical curve showing the temperature dependence of dielectric constant for $\mathrm{Ni}=0.04$ is shown in Figure 5 . The observed temperature dependence is consistent with
Debye-type of dispersion and can be explained using Debye equation expressed as [17]

$$
\varepsilon^{\prime}-\varepsilon_{\infty}=\left(\varepsilon_{0}-\varepsilon_{\infty}\right) /\left[1+\omega^{2} \tau^{2}\right]
$$

where $\varepsilon_{0}$ and $\varepsilon_{\infty}$ are the low and high frequency dielectric constant respectively, $\omega$ the angular frequency of the applied field and $\tau$, the relaxation time. Accordingly, there exist a high relaxation time at low temperature and hence we get a low dielectric constant as has been observed. At a higher temperature the thermal energy provided to the sample increases, thereby decreasing the relaxation time. Hence the dielectric constant increases.

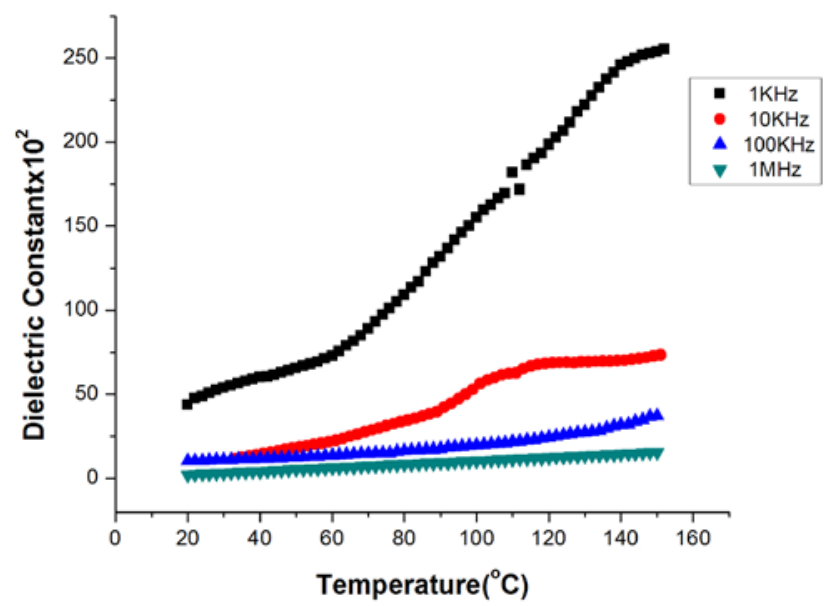

Figure 5. Variation of dielectric constant with temperature for $\mathrm{Ni}=0.04$

\section{Conclusion}

Li-Zn-Ni ferrite was successfully prepared by citrate precursor method. XRD confirm the spinel phase of the prepared ferrite samples. The lattices constant show a decrease while the theoretical densities show an increase with increasing Ni substitution. SEM analysis reveals that the particle size of the samples under investigation is in nanometer range. The values of dielectric constant at $10 \mathrm{KHz}$ show a decrease with increasing $\mathrm{Ni}$ ion concentration. It is also found that dielectric constant show dispersion with frequency whereas it is observed to increased with increasing temperature.

\section{References}

[1] Berry CC and Curtis, J Phys D: Appl. Phys, 36, R198, 2003.

[2] K. Vijaya Kumar, D.Paramesh, P. Venkat Reddy, M. Buchi Suresh, International Journal of Engineering \& Technology Research, 1, 153, 2013.

[3] Leena Jaswal, Brijesh Singh, J. Integr. Sci. Technol., 2(2), 69, 2014.

[4] V. Verma, V. Pandey, R.K. Kotnala, H. Kisan, N. Kumar, P.C. Kothari, J. Alloys Compd. 443, 178, (2007).

[5] C Sun, K Sun, Solid State Commun.,141, 258, 2007.

[6] G S Gopalakrishna, MJ Mahesh, KG Ashamanjari, MS Bhargava Ramu, Milina K, Ind. J. Phys., 84, 143, 2010.

[7] Z. Yue, J. Zhou, X.Wang, Z. Gui, L. Li, J. Eur. Ceram. Soc., 23, 189, 2003.

[8] X. Qi, J. Zhou, Z. Yue, Z. Gui, L. Li, J. Magn. Magn. Mater., 251, 316, 2002.

[9] C. Cannas, A. falqui, A. Musinu, D. Peddis, G. Piccaluga, J. Nano. Res., 8, 55, 2006. 
[10] I Soibam, S Phanjoubam, C Prakash, J. Alloys Compd., 475, 328, 2009.

[11] I Soibam, S Phanjoubam, H B Sharma, H N K Sarma and C Prakash, Ind. J. Phys., 83, 285, 2009.

[12] J Smit, HPJ Wijn, Ferrites (Philips Technical Library) Eindhoven, Netherland, 1959.

[13] AA Sattar, HM El-Sayed, WR Agami, AA Ghani, Am. J. Appl. Sci., 4, 89, 2007.

[14] B T Naughton, David R Clarke, J. Am. Ceram. Soc., 90, 3541, 2007.
[15] EJW Verwey and JH De Boer, Recl. Trav. Chim. Pays. Bass, 55, 331, 1936.

[16] EJW Verwey, PW Haayman and FC Romeijn J.Chem.Phys., 15, 181, 1947.

[17] S Chongtham, S. Phanjoubam, H.N.K. Sarma, R. Laishram, C. Prakash, Mod. Phys. Lett. B, 19, 899, 2005.

[18] M B Reddy, P.V. Reddy, Appl. Phys. (UK), 24, 975, 1991.

[19] AM Saikh, S.S. Bellad, B.K. Chougule, J. Magn. Magn. Mater., 195, 384, 1999.

[20] AK Singh, TC Goel, RG Mendiratta, J.Appl. Phys., 91, 6626, 2002. 